\title{
Land use dynamics and the environment
}

\author{
Carmen Camacho \\ CNRS, Université Paris 1 Panthéon-Sorbonne (France)* \\ Agustín Pérez-Barahona \\ INRA-UMR Économie Publique and École Polytechnique (France)
}

February 3, 2012

Preliminary and incomplete. Do not quote without permission.

\begin{abstract}
We build a model to study optimal land use, encompassing land use activities, pollution and climate change. This benchmark set-up allows us to identify the spatial drivers behind the interaction between land use and the environment. Pollution generates local and global damages since it flows across locations following a Gaussian Plume. In contrast to the previous literature on spatial dynamics, we prove that the social optimum problem is well-posed, i.e., the solution exists and is unique. We close the paper with a numerical analysis which illustrates the richness of our model, and its global dynamics. We study the different drivers of spatial heterogeneity. In particular, abatement technology stands out as a fundamental ingredient to achieve steady state solutions, which are compatible with the emergence of spatial patterns.
\end{abstract}

Keywords: Land use, Spatial dynamics, Pollution.

Journal of Economic Literature: C6; Q15; Q53; R1.

* Corresponding author at: CES, Maison des Sciences Economiques, 106/112, Boulevard de l'Hôpital, 75647 - Paris cedex 13, France; e-mail: Maria.Camacho-Perez@univ-paris1.fr 


\section{Introduction}

Land use activities are usually defined as the transformation of natural landscapes for human use or the change of management practices on human-dominated lands (Foley et al., 2005). It is widely accepted that these activities have greatly transformed the planet's surface, encompassing the existence and evolution of spatial patterns (see, for instance, Plantinga, 1996; Kalnay and Cai, 2003; and Chakir and Madignier, 2006). In this regard, Spatial Economics analyses the allocation of resources over space as well as the location of economic activity and, thus, the formation of spatial patterns. In particular, great attention has been devoted to questions such as firms' location, transport costs, trade, and regional and urban development (Duranton, 2007). However, the spatial drivers behind the interaction between land use and the environment are still far for being understood.

In this paper we contribute to the theoretical foundations of land use change and the environment by considering the interaction between land use activities, pollution and climate change. To this end we will develop a theoretical model that focuses on the spatial externalities of land use as drivers of spatial patterns.

There is an abundant literature on the interaction between land use, pollution and climate change. In particular, agricultural research has devoted great attention to the effects of pollution and climate change on agricultural land use. For instance, Heck et al. (1984), USEPA (1984) and Adams et al. (1986) have considered the adverse effects of air pollution on vegetation, including crops. Concerning climate change, it has been predicted overall a slight benefit to agricultural activities overall (see, among others, Adams, 1989; Deschênes and Greenstone, 2007; and Haim et al., 2011, for the US; and Olesen and Bindi, 2002, for Europe). However, Olesen and Bindi (2002), and Deschênes and Greenstone (2007) point out that there will be considerable spatial heterogeneity across states and countries in this regard. Moreover, these studies also recognize the necessity to consider other effects of climate change, such as on human health, sea level rise, soil degradation, biodiversity, etc.

About the effect of land use on pollution and climate change, Kalnay and Cail (2003) conclude that changes in land use due to urbanization and agriculture may explain the general increase in the minimum and slight decrease in the maximum surface temperature. Houghton et al. (1999), Houghton and Hackler (2001), Matson et al. 
(1997), and Tilman et al. (2001) have also identified significant environmental impacts of land use. Moreover, Foley et al. (2005) point out that the effects of environmental degradation due to land use are global but also regional/local.

Although this literature has been very fruitful, the dominant approach was empirical. Therefore, there is a general agreement about the lack of explicit modelling of the spatial drivers behind the interaction between land use, pollution, and climate change. Closely related to the integrated assessment approach, bottom-up models of agricultural economics (for instance, de Cara and Rozakis, 2004; de Cara et al., 2005; and Havlík et al., 2011) have contributed to the understanding of the spatial drivers of land use. However, these models focus on partial equilibrium (mainly the supply side) and do not completely consider the intertemporal decisions of the problem. In this paper we use an alternative approach based on Dynamic Spatial Theory (see Desmet and Rossi-Hansberg, 2010, for a survey). Although this approach was only recently developed, it is based on an old and central question in economic theory: the optimal and market allocation of the economic activity across space (see the seminal works of Hotelling, 1929; and Salop, 1979).

The construction of an economic framework encompassing space and time is not an easy task. We can underline three distinct sets of models with continuous time and space. The natural spatial generalization of the Ramsey model is presented in Brito (2004) and Boucekkine et al. (2009). Both include a policy maker who decides the trajectory for consumption at each location. The main feature of these models is the spatial dynamics of capital, which flows in space to meet optimal decisions according to a partial differential equation. Although these sophisticated models are promising, one cannot ensure in general either existence or uniqueness of solutions (i.e., ill-posed problem in the sense of Hadamard, 1923). There are then two pragmatic alternatives. First, one can consider myopic agents. This is the approach followed by Desmet and Rossi-Hansberg (2009 and 2010). Although each location solves a static problem, their model is dynamic in time. Indeed, each location decides the optimal amount to consume, how much to invest in R\&D, and how much to save, taking land revenues, prices and salaries as given. Finally, all savings are coordinated by a cooperative that invests along the space. Second, one can prevent physical capital mobility but allow for spatial externalities. In Brock and Xepapadeas (2008b) there is technological diffusion since aggregated neighbouring capital affects the location's production. 
Brock and Xepapadeas (2008a and 2010) and Xepapadeas (2010) study the concept of diffusion in an environmental context, focusing on state variables that diffuse over the space. In particular, they find that diffusion-induced instability may create spatial patterns in infinite horizon optimal control problems. The identification of this spatial driver is an important contribution to spatial dynamics. Moreover, they also provide a framework and useful tools to study local stability in a continuum of spatial sites.

In this paper we will make use of this new theory on spatial dynamics in order to understand the spatial drivers behind land use and the environment. To our knowledge, our paper provides a first analytically tractable general equilibrium framework of land use that encompasses (i) spatial and time dimensions which are presented in a continuous manner, (ii) spatial externalities due to pollution and abatement activities, and (iii) environmental degradation and climate change.

Our starting point is the Spatial Ramsey model introduced by Brito (2004) and Boucekkine et al. (2009). We propose a model in continuous time and space to study optimal land use. Each location is endowed with a fixed amount of land, which is allocated among production, pollution abatement, and housing. Although the unique production input (land) is spatially immobile by nature, this is a model of spatial growth. ${ }^{1}$ Indeed, locations' actions affect the whole space through pollution and climate change. We assume that the production of the final good generates local pollution, which flows across locations. ${ }^{2}$ In this regard, we illustrate the diffusion mechanism by means of the well-known Gaussian Plume equation (see Sutton, 1947a and 1947b). We also consider that local pollution participates in global pollution. In particular, in our model, the effect of global pollution may be interpreted as climate change (e.g., anthropogenic GHGs). Finally, both local and global pollution can damage production.

In contrast to Boucekkine et al. (2009), Brock and Xepapadeas (2008a,b and 2010), and Xepapadeas (2010), we prove the existence and unicity of a social optimum, i.e., our problem is well-posed. We provide the corresponding Pontryagin conditions, which turn out to be necessary and sufficient. To illustrate the richness of our model, we continue

\footnotetext{
${ }^{1}$ In this simplified set-up, the land devoted to abatement may be interpreted as pollution removal due to, for instance, prairies and forests (see de Cara and Rozakis, 2004; de Cara et al., 2005; Nowak et al., 2006; and Ragot and Schubert, 2008). In general, one can also consider that abatement facilities will require land (i.e., physical space), which is the single production factor.

${ }^{2}$ According to Akimoto (2003) two well-known examples of intercontinental transport pollution are the tropospheric ozone and the CO.
} 
our analysis through numerical simulations. To this end, we adapt an algorithm first developed in Camacho et al. (2008) to the current problem. With this numerical tool in hand, we study the role of technological progress in production and abatement activities, population density, land endowment, spatial heterogeneity of land productivity, and spatially differentiated sensibility to pollution and climate change. In particular, we focus on the creation of long-term spatial patterns and on the optimal decisions to palliate the negative effects of pollution on productivity under different scenarios. Our algorithm uses a finite difference approximation of the Pontryagin conditions of our problem, simulating then the optimal trajectories for all variables. Alternatively to the linear quadratic approximation of Brock and Xepapadeas (2008a,b and 2010) and Xepapadeas (2010), we would like to underline that our analysis is global: we obtain a simulation of the entire trajectory of the states, controls, and co-states from their initial distributions until they eventually reach (or not) a steady state.

The paper is organized as follows. In section 2 we explain the Gaussian Plume that describes the pollution dynamics in our set-up. We present the economic model in section 3. Section 4 provides the Pontryagin conditions as well as the results of existence and unicity of social optimum. In section 5 we consider the numerical exercises. Finally, section 6 concludes.

\section{The Gaussian plume}

In this paper we introduce the dynamics of pollution in a model of spatial economics for the first time. The dynamics of pollution are described by means of a well-known model in physics called the Gaussian plume.

The Gaussian plume is a standard set-up of atmospheric dispersion that introduces a mathematical description of the transport of airborne contaminants. Roberts (1924) and Sutton (1932) were the first to study the atmospheric dispersion problem. Since then great effort has been devoted to provide analytical solutions to the problem (see, for instance, Arya, 1999, Caputo et al., 2003, and Stockie, 2011). The simplest of these solutions is the Gaussian plume, which has been mainly applied to air pollutants. However, it can be also used to study the dispersion of pollutants in aquifers and porous soils and rocks (Freeze and Cherry, 1979, and French et al., 2000), as well as nuclear contaminants (Jeong et al., 2005, and Settles, 2006). 
Let us introduce the main equations of a Gaussian plume by means of considering the example of a pollutant emitted by a single source located at $x \in \mathbb{R}^{3}$. According to this model, the dynamics of the pollution at location $x$ in time $t, p(x, t)$, is given by the following second-order partial differential equation (PDE) of parabolic type:

$$
p_{t}(x, t)+\nabla \cdot J(x, t)=E(x, t),
$$

where $p_{t}(x, t)$ denotes $\partial p(x, t) / \partial t, E(x, t)$ are the emissions of the single source in time $t \geq 0, \nabla$ is the gradient, and $J(x, t)$ represents the flux of contaminant. This flux usually comprises the effect of diffusion and/or advection. Diffusion describes the spread of a pollutant through regions of high concentration to regions of low concentration. In this regard, one can assume that the diffusive flux is proportional to the pollution gradient (Fick's law), i.e., $J_{D}=-D \nabla p$, where $D$ is a parameter that represents the diffusion coefficient of the physical environment (air, water, soils, rock, etc.). The second component of the flux is the advection due to wind, which is usually represented by $J_{A}=p v$, where $v$ is the wind velocity. Therefore, $J=J_{A}+J_{D}=p v-D \nabla p$.

As pointed in the introduction, our model is based on the Spatial Ramsey model introduced by Brito (2004) and Boucekkine et al. (2009). Our set-up requires a slightly modified Gaussian plume. In particular, the former plume in (1) considers a single pollution source, where emissions are usually assumed to be exogenous and constant in time. Moreover, these plumes are often studied just at the steady state. In contrast to that, our model assumes a continuum of immobile sources, where emissions may change with time and are part of the policy maker's decisions. Moreover, our analysis studies both the dynamic transition and the steady state.

For the sake of analytical tractability we also consider several simplifications. First, our paper focuses mainly on the case $x \in \mathbb{R}$, i.e., space is unidimensional. Second, we assume that advection is implicitly included in the diffusion effect. ${ }^{3}$ Finally, it is assumed $D=1$ in order to illustrate the problem. Therefore, the dynamics of pollution at location $x$ is described by the following Gaussian plume:

$$
p_{t}(x, t)-p_{x x}(x, t)=E(x, t),
$$

\footnotetext{
${ }^{3}$ For Gaussian plumes that include advection see, for instance, Arya (1999) and Stockie (2011). Our model does not explicitly consider advection because it would require further physical assumptions that are beyond the scope of this paper (e.g., wind velocity and direction, and its spatial and time variability). Moreover, the effect of advection is negligible in cases of pollution transportation in soils, rocks, etc.
} 
where $p_{x x}$ denotes $\partial^{2} p / \partial x^{2}$.

\section{The model}

We assume that space is the real line $\mathbb{R}$ so that there exists a continuum of locations. Each location has a unit of land, which can be devoted to three different activities: production, housing and pollution abatement. For simplicity, we shall assume that the space required for housing at each location is equal to its population density. There exists a unique consumption good the production of which only requires land and which we denote by $F(l)$. Finally, the remainder of the land is used to abate air pollution $G(1-l-f(x))$. Notice that all production technologies can be space dependent.

Pollution has two dimensions in the model we present. The local dimension (e.g., air pollution) damages individuals health and comes directly from the production of the consumption good. The pollutant travels across space following the Gaussian plume equation described in (2). On top of this, when the pollutant stays in the atmosphere it induces global warming which has global effects. We make the distinction then between these two aspects of pollution, local and global, since damages coming from airpollution and from global warming are clearly different. Global pollution is naturally defined as

$$
P(t)=\int_{\mathbb{R}} p(x, t) d x .
$$

We introduce pollution damages in production using a damage function $\Omega(p, P, x)$, which represents the share of foregone production due to local and global pollution. If we denote by $A(x, t)$ total factor productivity at location $x$ at time $t$, we have that this location produces $\Omega(p, P, x) A(x, t) F(l)$ units of final good when it devotes an amount $l$ of land to production. For simplicity reasons we shall assume that the abatement technology is not affected by pollution. In the remaining of the paper we make the following assumptions regarding the production functions:

(A1) Functions $F$ and $G$ are positive, increasing, concave, and their first and second derivatives exist and are positive, that is:

$$
\begin{aligned}
& F(\cdot) \in C^{2}, \quad F(0)=0, \quad F^{\prime}(\cdot)>0, \quad F^{\prime \prime}(\cdot) \leq 0, \quad \lim _{s \rightarrow 0} F^{\prime}(s)=\infty, \lim _{s \rightarrow \infty} F^{\prime}(s)=0, \\
& G(\cdot) \in C^{2}, \quad G(0)=0, \quad G^{\prime}(\cdot)>0, \quad G^{\prime \prime}(\cdot) \leq 0, \quad \lim _{s \rightarrow 0} G^{\prime}(s)=\infty, \lim _{s \rightarrow \infty} G^{\prime}(s)=0 .
\end{aligned}
$$


(A2) $\Omega(p, P, x) \in C^{2,2}$, i.e., it is twice differentiable with respect to $p$ and $P$, decreasing in each factor $\Omega_{1}(p, P, x)<0, \Omega_{2}(p, P, x)<0$. Function $\Omega(p, P, x)$ is defined on $\mathbb{R}^{+} \times \mathbb{R}^{+}$and takes values in $[0,1]$.

We assume that the policy maker collects all production and re-allocates it across locations at no cost:

$$
\int_{\mathbb{R}} c(x, t) f(x) d x=\int_{\mathbb{R}} \Omega(p, P, x) A(x, t) F(l) d x,
$$

where $c(x, t)$ denotes consumption per capita at location $x$ and time $t$. This assumption enlarges the set of feasible abatement and production decisions with respect to the case in which each location has to produce its own consumption.

The policy maker chooses consumption per capita and the use of land at each location, which maximize the discounted welfare of the entire population. We introduce (as in Boucekkine et al., 2009) two discount functions, a spatial discount function which we identify to the population density function, and a standard temporal discount function as in the usual Ramsey model. The policy maker maximizes:

$$
\max _{\{c, l\}} \int_{0}^{\infty} \int_{\mathbb{R}} u(c(x, t)) f(x) g(t) d x d t
$$

subject to

$$
\mathcal{P}\left\{\begin{array}{l}
p_{t}(x, t)-p_{x x}(x, t)=\Omega(p, P, x) A(x, t) F(l(x, t))-G(1-l-f(x)) \\
\int_{\mathbb{R}} c(x, t) f(x) d x=\int_{\mathbb{R}} \Omega(p, P, x) A(x, t) F(l) d x \\
P(t)=\int_{\mathbb{R}} p(x, t) d x \\
p(x, 0)=p_{0}(x) \geq 0 \\
\lim _{x \rightarrow\{ \pm \infty\}} p_{x}(x, t)=0
\end{array}\right.
$$

where $(x, t) \in \mathbb{R} \times[0, \infty)$. 


\section{Pontryagin conditions, existence and uniqueness results}

In this section we present the theoretical contributions of our paper. First, we prove the existence of at least one solution to the dynamical system $\mathcal{P}$. This result is not a straightforward application of existing results (Camacho et al., 2008) because of some special features of $\mathcal{P}$. In the present model, there exists a global variable $P$, defined as the spatial integral of $p$, together with the restriction posed on consumption. In contrast to previous articles, in this model the policy maker gathers all production to distribute it later, adding the afore mentioned additional integral constraint on consumption. In the proof of proposition 1 we transform the integral constraints into partial differential equations. Then we apply theorem 12.1 in chapter 8 in Pao (1992) to close the proof.

Proposition 1 Under assumption (1), system $\mathcal{P}$ has at least a solution.

Proof : See the appendix A.

We use the method of variations in Raymond and Zidani $(1998,2000)$ to obtain the Pontryagin conditions of problem (4)-(5). We write the associated value function $V$ as a function of $c, l, p$ and $P$ as follows:

$$
\begin{aligned}
& V(c, l, p, P)=\int_{\mathbb{R}^{+}} \int_{\mathbb{R}} u(c(x, t)) f(x) g(t) d x d t- \\
& -\int_{\mathbb{R}^{+}} \int_{\mathbb{R}} q(x, t) g(t)\left[p_{t}(x, t)-p_{x x}(x, t)-\Omega(p, P, x) A(x, t) F(l(x, t))+G(1-l-f(x))\right] d x d t- \\
& -\int_{\mathbb{R}^{+}} m(t) g(t)\left(P(t)-\int_{\mathbb{R}} p(x, t) d x\right) d t- \\
& -\int_{\mathbb{R}^{+}} n(t) g(t)\left(\int_{\mathbb{R}} c(x, t) f(x) d x-\int_{\mathbb{R}} \Omega(p, P, x) A(x, t) F(l(x, t)) d x\right) d t .
\end{aligned}
$$

Functions $q, m$ and $n$ are auxiliary functions. If there exists an optimal solution $\left(c^{*}, l^{*}, p^{*}, P^{*}\right)$, then any other solution to problem (4)-(5) can be written as a deviation from the optimal solution as

$$
\begin{aligned}
& c(x, t)=c^{*}(x, t)+\epsilon \kappa(x, t), \\
& l(x, t)=l^{*}(x, t)+\epsilon L(x, t), \\
& p(x, t)=p^{*}(x, t)+\epsilon \pi(x, t), \\
& P(t)=P^{*}(t)+\epsilon \Pi(t) .
\end{aligned}
$$


To obtain the Pontryagin conditions, we take the first order derivative of $V$ with respect to $\epsilon$, in the spirit of minimizing the distance to the optimal solution. As a result, we obtain a reverse time parabolic PDE, which describes the dynamics of the shadow price of pollution, together with a static equation associated with optimal land allocation at each $(x, t)$. Finally, the set of first order conditions also contains spatial boundary conditions on $q$ and a terminal condition on $p q$ :

Proposition 2 The Pontryagin conditions of problem (4)-(5) are:

$$
\left\{\begin{array}{l}
p_{t}(x, t)-p_{x x}(x, t)=\Omega(p, P, x) A(x, t) F(l(x, t))-G(1-l-f(x)), \\
q_{t}(x, t)+q_{x x}(x, t)=\left(\Omega_{1}(p, P, x)+\frac{1}{f(x)} \Omega_{2}(p, P, x)\right) A(x, t) F(l)\left[u^{\prime}\left(\frac{\Omega(p, P, x) A(x, t) F(l)}{f(x)}\right)+q(x, t)\right], \\
{\left[u^{\prime}(c(x, t))+q(x, t)\right] \Omega(p, P, x) A(x, t) F^{\prime}(l)+q(x, t) G^{\prime}(1-l-f(x))=0,} \\
c(t) \int_{\mathbb{R}} f(x) d x=\int_{\mathbb{R}} \Omega(p, P, x) A(x, t) F(l) d x, \\
P(t)=\int_{\mathbb{R}} p(x, t) d x, \\
p(x, 0)=p_{0}(x) \geq 0, \\
\lim _{x \rightarrow\{ \pm \infty\}} p_{x}(x, t)=0, \quad \lim _{x \rightarrow\{ \pm \infty\}} q_{x}(x, t)=0, \\
\lim _{t \rightarrow \infty} p(x, t) q(x, t)=0,
\end{array}\right.
$$

for $(x, t) \in \mathbb{R} \times[0, \infty)$.

Proof : See the appendix B.

The following corollary shows an expected result: consumption per capita is identicall across locations. Indeed, one could expect homogeneity since the policy maker does not have any location preference.

Corollary 1 Consumption per capita is spatially homogeneous, i.e. $c(x, t)=c(t)$.

Proof : See the appendix C.

The next step is to prove that our problem is well-posed, in stark contrast to other papers in spatial economics in continuous time and space. In previous papers the problem was that of a policy maker maximizing the welfare of a region in a period of time, where the state variable is always physical capital, $k$, and there is no other 
production factor and no externality. In the end, the set of Pontryagin conditions is made of the parabolic PDE for $k$, a reverse parabolic PDE for its shadow price, $q$, plus transversality conditions in space for $k_{x}, q_{x}$ and a terminal condition on $p q$ for all $x \in \mathbb{R}$. As noted in Boucekkine et al. (2008), the resulting system is ill-posed in the sense of Hadamard: one can prove neither existence nor uniqueness of a solution. Indeed, in classical growth models without space there exists a unique relationship between the initial condition and the terminal state of the co-state variable. Hence the terminal condition helps recover the unique initial condition for the co-state which makes $q$ satisfy the terminal condition. When we deal with spatial models, the solution for $q$ at $(x, t)$ depends on its initial distribution $q_{0}$ through an integral plus an integral form dependant on the values of $k$ and $q$ :

$$
q(x, t)=\int_{\mathbb{R}} q_{0}(x) d x+\int_{\mathbb{R}} \int_{\mathbb{R}^{+}} Q(q, k, c) d x d t .
$$

Consequently, there exist infinite possibilities for $q_{0}$ that make $p q$ satisfy the terminal condition.

In the present problem, we have more information that helps us pick a unique initial distribution for $q$. Desmet and Hansberg-Rossi (2010) overcome ill-posedness in a spatial set-up. On the one hand, their agents are myopic solving a static problem at each moment in time. On the other, they impose more structure to their problem by means of a cooperative managing aggregated savings. In our setup, the introduction of a spatially fixed production factor $l$ allows us to show that the solution is unique.

Proposition 3 The problem (4)-(5) is well posed: its solution exists and is unique.

Proof: We prove that although the initial distribution for $q, q_{0}(x)=q(x, 0)$ is not provided by the first order conditions, it is however unique. We begin by exploiting the first order condition obtained in the proof of corollary 1:

$$
m(t)=\frac{1}{f(x)} \Omega_{2} A F(l)(q+n) .
$$

Equation (9) implies that $\frac{1}{f(x)} \Omega_{2} A F(l)(q+n)$ is independent of $x$, so that

$$
\frac{\partial}{\partial x}\left(\frac{1}{f(x)} \Omega_{2} A F(l)\left(q+u^{\prime}(c)\right)\right)=0 .
$$


If $A(x) \neq 0, \forall x \in \mathbb{R}$ and $q+u^{\prime}(c) \neq 0$ for all $(x, t)$ then

$$
\Omega_{2} A F\left(q+u^{\prime}(c)\right)\left(\frac{-f^{\prime}}{f}+\frac{\Omega_{2,3}}{\Omega_{2}}+\frac{\Omega_{2,1}}{\Omega_{2}} p_{x}+\frac{A_{x}}{A}+\frac{F^{\prime}}{F} l_{x}+\frac{q_{x}}{q+u^{\prime}(c)}\right)=0 .
$$

Hence,

$$
\frac{-f^{\prime}}{f}+\frac{\Omega_{2,3}}{\Omega_{2}}+\frac{\Omega_{2,1}}{\Omega_{2}} p_{x}+\frac{A_{x}}{A}+\frac{F^{\prime}}{F} l_{x}+\frac{q_{x}}{q+u^{\prime}(c)}=0 .
$$

If $q+u^{\prime}(c)=0$, using that $q\left(\Omega A F^{\prime}+G^{\prime}\right)+u^{\prime}(c)\left(\Omega A F^{\prime}\right)=0$ (see proof of proposition 2 in the appendix B), we find that $q G^{\prime}=0$. Given assumption (A1), this last equality implies that $q=0$, which leads to a corner solution. Let us focus then on the interior solutions and assume that $q+u^{\prime}(c) \neq 0$.

Our next step is to consider the following couple of equations evaluated at $t=0$ :

$$
\left\{\begin{array}{l}
\frac{-f^{\prime}}{f}+\frac{\Omega_{2,3}}{\Omega_{2}}+\frac{\Omega_{2,1}}{\Omega_{2}} p_{x}+\frac{A_{x}}{A}+\frac{F^{\prime}}{F} l_{x}+\frac{q_{x}}{q+u^{\prime}(c)}=0 \\
q\left(\Omega A F^{\prime}+G^{\prime}\right)+u^{\prime}(c)\left(\Omega A F^{\prime}\right)=0
\end{array}\right.
$$

where $u^{\prime}(c)=u^{\prime}\left(\frac{\int_{\mathbb{R}} \Omega(p, P, x) A(x, t) F(l) d x}{\int_{\mathbb{R}} f(x) d x}\right)$. We shall first prove that given an initial distribution for $p, p_{0}(x)=\{p(x, 0): x \in \mathbb{R}\}$, we can obtain from the second equation in (10) a unique solution of $l(x, 0)$ as a function of $q(x, 0), l(q)$. We replace then $l(q)$ into the first equation in (10). The argument will end here since we face an ordinary differential equation with the condition $\lim _{x \rightarrow\{ \pm \infty\}} q_{x}=0$.

Let us then prove that $q\left(\Omega A F^{\prime}+G^{\prime}\right)+u^{\prime}(c)\left(\Omega A F^{\prime}\right)=0$ has a unique solution for $l$ as a function of $q$. We can rewrite the equation as

$$
\left(q+u^{\prime}(c)\right) \Omega A F^{\prime}=-q G^{\prime}
$$

If $q>0$, then there is no solution to our problem. This is by no means a problem since $q$ plays the role of the co-state variable of pollution. As co-state variable of pollution, we actually expect $q$ to be negative. We focus then on the case of $q<0$, for which a solution to our problem exists. When $q+u^{\prime}(c)<0$ there is no solution to our problem. There remains the case $q+u^{\prime}(c)>0$. In this case the left hand side of (11) tends to $\infty$ when $l$ tends to 0 , and tends to a constant when $l=1-f(x)$ :

$$
\left\{\begin{array}{l}
\lim _{l \rightarrow 0}\left(q+u^{\prime}(c)\right) \Omega A F^{\prime}=\infty \\
\lim _{l \rightarrow 1-f(x)}\left(q+u^{\prime}(c)\right) \Omega A F^{\prime} \in \mathbb{R} .
\end{array}\right.
$$


Similarly, the right hand side of (11) equals a positive constant for $l=0$, and tends to $\infty$ when $l=1-f(x)$ :

$$
\left\{\begin{array}{l}
\lim _{l \rightarrow 0}\left(-q G^{\prime}\right) \in \mathbb{R}, \\
\lim _{l \rightarrow 1-f(x)}\left(-q G^{\prime}\right)=\infty .
\end{array}\right.
$$

Then, the two functions $\left(q+u^{\prime}(c)\right) \Omega A F^{\prime}$ and $-q G^{\prime}$ cross at a unique $l \in(0,1-f(x))$.

The existence of a unique solution actually guarantees that the Pontryagin conditions are not only necessary but also sufficient.

\section{$5 \quad$ Numerical exercises}

Due to the complexity of the Pontryagin conditions (8), we illustrate the richness of our model by means of a numerical analysis. Appendix D provides a description of the computational setting and our algorithm to solve (8). We will focus on the emergence of spatial patterns. In particular, we study the drivers of spatial heterogeneity, analysing their persistence in time: are all disparities equally persistant? What are the spatial differences that do not vanish with time? Can inequality arise in an initially equally endowed world?

Our numerical exercise is divided in two parts: sections (5.1)-(5.3) consider that population follows a uniform distribution, while section (5.4) assumes a Gaussian distribution in order to study the effect of population agglomeration. The parameter values are provided in Table 1. For illustration purposes we consider that locations land endowment, $L$, is equal to 300 , and that total population is equal to $110 .{ }^{4} \mathrm{We}$ would like to underline that the values provided in this table aim at illustrating our model, and they do not correspond to any specific situation since we shall focus on the qualitative properties of our set-up.

We assume that space is a line of length 5 divided into 500 locations. The time horizon varies from 10 to 40 depending on the convergence speed of the variables.

\footnotetext{
${ }^{4}$ Both time horizon and space are finite in numerical exercises. This implies that total population does not need to be equal to 1 since the integral in the objective function converges in this finite framework. Therefore, taking advantage of this, we increase both total population and land endowment in order to enlighten our numerical results.
} 


\begin{tabular}{lll}
\hline$B$ & Minimum productivity & 0.5 \\
$A$ & Max. productivity increase & 10 \\
$D$ & Cleaning productivity & 0.1 \\
$\rho$ & Time discount rate & 0.05 \\
$\gamma_{1}$ & $P$ damage & 0.005 \\
$\gamma_{2}$ & $p$ damage & 0.005 \\
$\alpha$ & Cobb-Douglas parameter & 0.75 \\
$L$ & Locations' land endowment & 300 \\
$p_{0}$ & Initial pollution at $x$ & 100 \\
& Total Population & 110 \\
\hline
\end{tabular}

Table 1: Parameter values for the numerical exercises.

Agents preferences are given by a logarithmic utility function. We have a Cobb-Douglas production function for the final good. The net productivity is $B+A \Omega(p, P, x)$ with $\Omega(p, P, x)=e^{-\gamma_{2} p-\gamma_{1} P s(x)}$. Following Weitzman (2009), $\Omega$ is an exponential damage function, taking values in the interval $[0,1]$. We consider that local and global pollution ( $p$ and $P$, respectively) harm productivity, where $\gamma_{1}$ and $\gamma_{2}$ are constants: for given $(p, P)$, the fraction $1-A \Omega(p, P, x)$ represents the foregone productivity at location $x$. For the sake of simplicity we assume that both $A$ and $B$ are constant in space and time. Moreover, $s(x)$ stands for the sensibility of location $x$ to global pollution. Assuming a linear abatement technology, we have $G(l)=D l$.

We consider in all scenarios that initial pollution is uniformly distributed. We believe of no particular interest the case when the only spatial feature is the initial distribution of pollution. Obviously, any difference in the initial endowment of pollution vanishes with time if all other variables are spatially homogeneous.

\subsection{The benchmark scenario}

We begin our analysis with the benchmark scenario in which population is evenly distributed on space. It is the objective of this benchmark to underline the tradeoff between production and abatement. Accordingly, we have chosen a uniform distribution of population which gives 0.22 people per location. They need 0.22 units of land for housing which is not critical when total land endowment is 300 . We consider the effect 
of population agglomeration and the subsequent accrued need for housing in section 5.4. We further assume that spatial sensibility to pollution is constant in space, i.e., $s(x)=1$ for all $x$. Figure 1 shows the results.
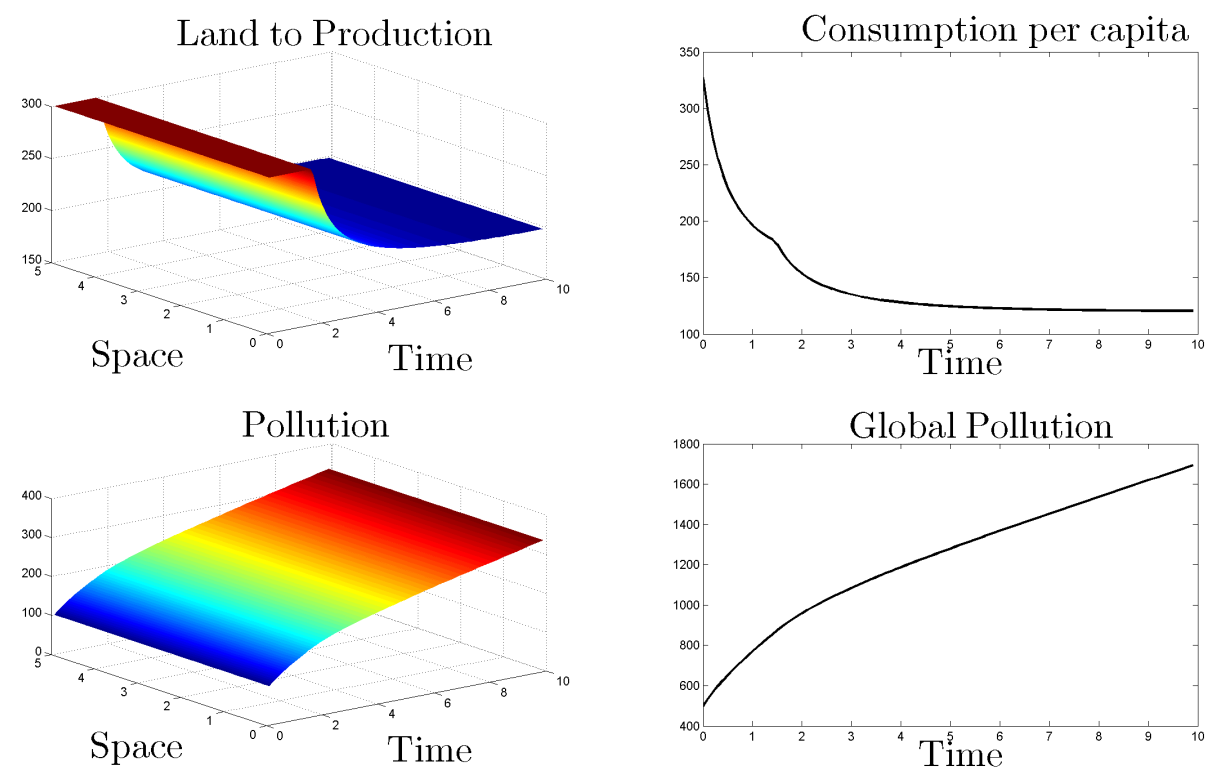

Figure 1: Benchmark scenario.

Given that there are no spatial disparities, it is not surprising that the optimal trajectories are uniform in space. The allocation of land to production starts at its highest possible level (a corner solution) and it remains at this level until the environmental damage is large enough. Then land to production is optimally reduced, thus devoting part of the land endowment to abatement. Consumption observes a decreasing trajectory, reaching a steady state, while pollution grows steadily.

The optimal land trajectory attains its steady state after 5 periods. Despite using $2 / 3$ of land to production, the economy cannot keep the initial level of consumption in the long-run due to the damage caused at the beginning. Both types of pollution cause everlasting damage that current abatement cannot make disappear completely. However, abatement is used as a stability measure to reach the steady state. Let us study in the next sections the different ingredients of our model. 


\subsection{Role of abatement technology}

We consider now a simple case of heterogeneous abatement technology, in which there exist two regions of equal size. The productivity of abatement technology in the first region is equal to 0.2 , that is to say, twice the abatement productivity in the second region:

$$
D(x)=\left\{\begin{array}{lll}
0.2, & \text { if } & x \in[0,2.5] \\
0.1, & \text { if } & x \in[2.5,5] .
\end{array}\right.
$$

The results are displayed in figure 2 .
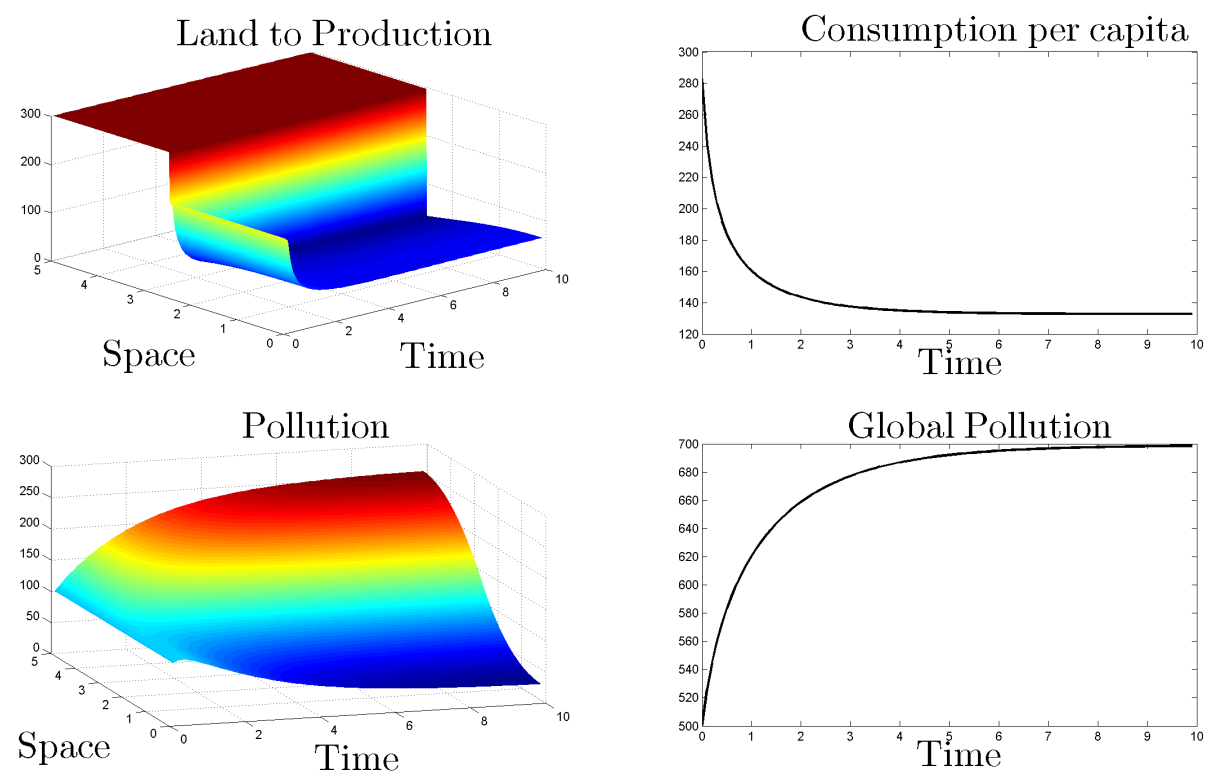

Figure 2: Role of abatement technology.

The heterogeneity in abatement induces heterogeneity in land allocation from the beginning. Indeed, at time zero land to production is a step function, in which the less advanced region in abatement fully specialises in production (reaching a corner solution). At the same time, the most advanced region devotes around half its endowment to production and half to abatement activities. With time, the most advanced region gets more specialised in abatement due to the increasing levels of pollution. Moreover, one should also observe that within the advanced region, spatial differences arise. Locations close to the border with the less advanced region need to devote more land to abatement in order to alleviate the pollution inflow coming through the frontier. 
Notice that these spatial differences would be magnified if the pollutant under study moved slower.

As a consequence of the allocation of land, local pollution is heterogenous in space. All locations in the less advanced region emit the same. However, the closer the location is to the advanced region the lower their level of local pollution. The level of local pollution in the advanced region is also heterogenous due to the inflow from the less advanced region. Even if the advanced locations at the border devote the largest share of land to abatement, they end up with the highest pollution level of their region.

Finally, the economy reaches a steady state in all variables. Hence, permanent differences in abatement technology induce lasting heterogeneity in land allocation and local pollution.

\section{- Local and global damage}

In the previous scenarios, we have considered that both local and global pollution causes the same damage per unit (i.e., $\gamma_{1}=\gamma_{2}$ ). Let us study now the case of contaminants with only local or global effects. ${ }^{5}$

When damage is only local, $\gamma_{1}=0$ in $\Omega$. Since damage does not depend on global pollution, which is the largest pollutant, total damage is lower than in the previous case. As a consequence, one can see in figure 3 that locations do not abate at first. However, when local pollution gets to a high enough level, the most advanced regions in abatement start abating. At the end, the economy reaches a steady state, which is qualitatively identical to the previous case.

Finally, let us consider the situation where the damage is only global $\left(\gamma_{2}=0\right.$ in $\Omega$ ). Due to the greater pollution damage, the abatement specialisation of the most advanced region is faster than in the case of a pollutant with only local damage. Nevertheless, the qualitative behaviour of the optimal trajectories is similar to figure 3. The only

\footnotetext{
${ }^{5}$ The results of these scenarios are qualitatively equivalent to the case of pollutants with a mainly local $\left(\gamma_{2}>\gamma_{1}\right)$ or global $\left(\gamma_{2}<\gamma_{1}\right)$ effect. Well-known pollutants with only global effects are $\mathrm{CO}_{2}$ and stratosphere ozone. Air contaminants in general (including tropospheric ozone, $\mathrm{NO}_{x}$, and $\mathrm{CO}_{2}$ plumes) are examples of local pollutants that flow among locations. Moreover, Akimoto (2008) points out methane and $\mathrm{CO}$ as examples of transboundary contaminants with both local and global effects. In particular, $\mathrm{CO}$ affects the oxidizing capacity of the atmosphere, raising the lifetime of greenhouses and climate change.
} 

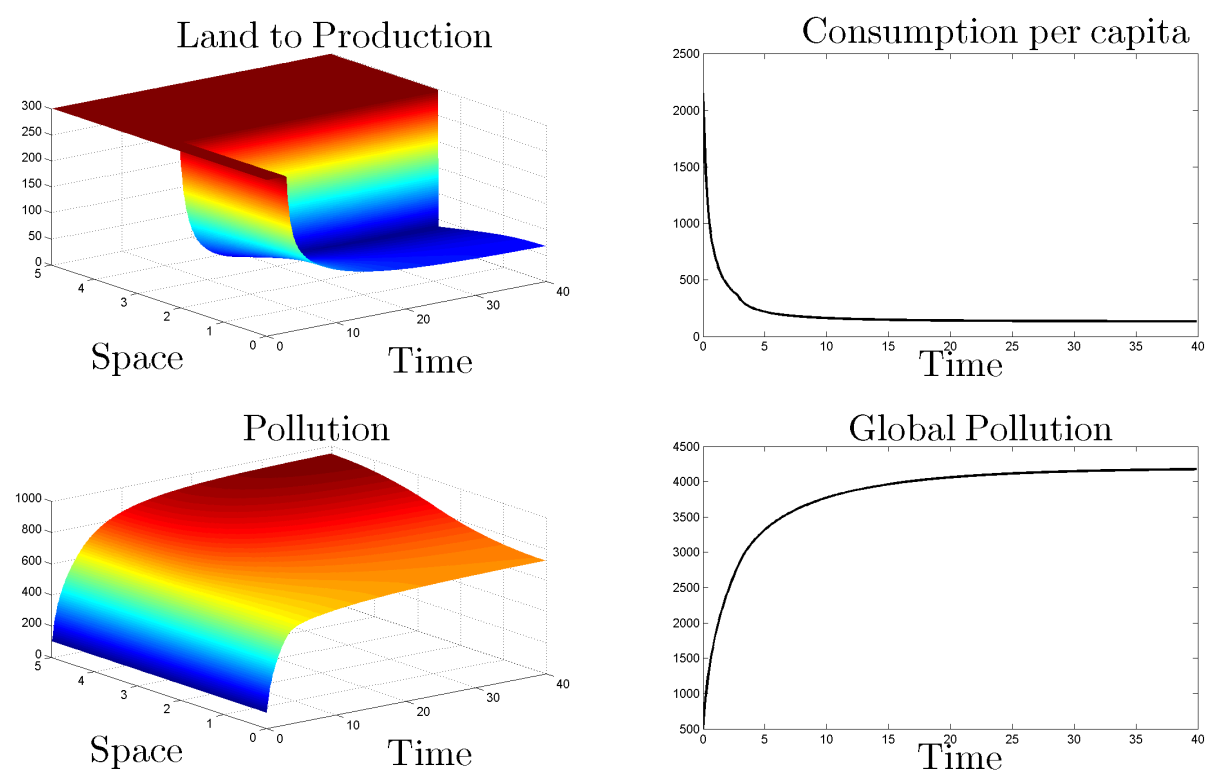

Figure 3: Damage function only depends on local pollution $\left(\gamma_{1}=0\right)$.

differences are, indeed, a faster abatement specialisation and a lower level of both local and global pollution.

\subsection{Spatially heterogeneous damage}

In this section we modify the benchmark model considering that the sensibility to pollution $s(x)$ is heterogenous in space. We study the situation in which $s(x)$ is a step function so that

$$
s(x)= \begin{cases}1, & \text { if } \quad x \in[0,2.5] \\ 5, & \text { if } x \in[2.5,5]\end{cases}
$$

This scenario is consistent with the current concern with the impact of the sea level rise on coastal zones (see, among others, Nicholls and Cazenave, 2010; and Nicholls et $a l ., 2011)$. In this regard, one can interpret the most sensible region, $s(x)=5$, as the coastal area, while $s(x)=1$ would correspond to the inland.

Figure 4 shows that, at the beginning, production is larger in the less sensitive region. However, soon afterwards, this region reduces the land devoted to production, becoming spatially homogeneous at the steady-state. This result goes against the $\grave{a}$ priori belief that most sensitive regions would produce less in order to preserve their 


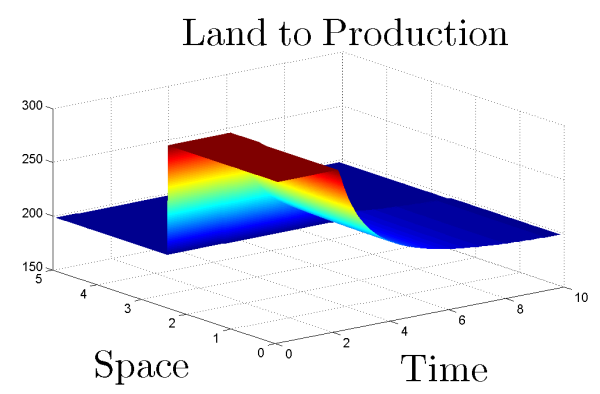

Pollution

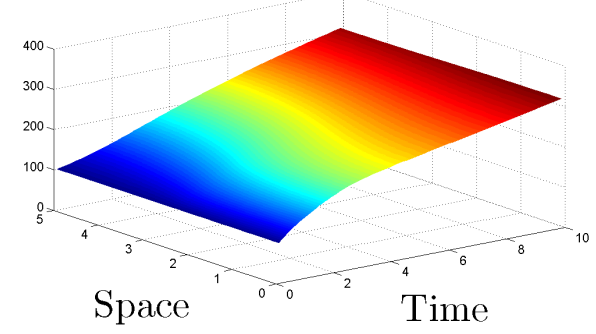

Consumption per capita

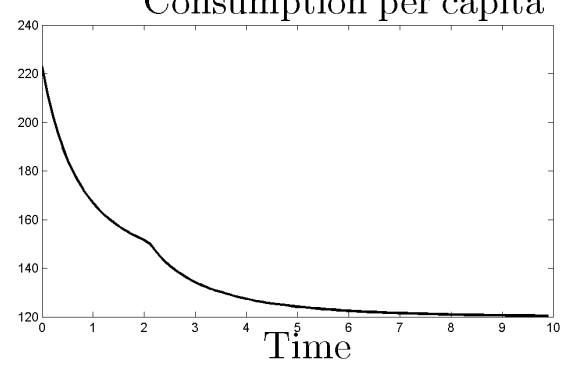

Global Pollution

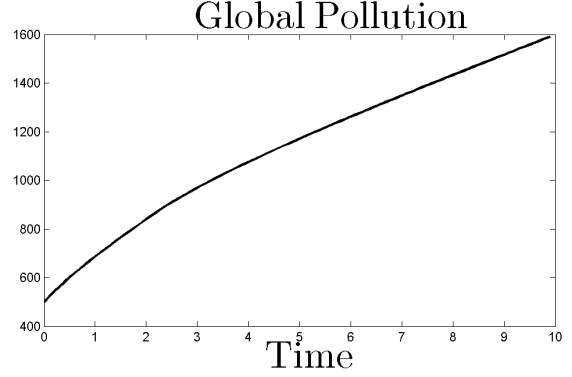

Figure 4: Spatially heterogeneous damage.

environmental quality. Since pollution flows over the space, even regions with nonexistent or little production will experience positive levels of local pollution. Therefore, the less sensitive regions optimally reduce their production and devote some land to abatement. Moreover, if the most sensitive regions had been endowed with better abatement technology, then they would have devoted more land to abatement relatively to the less sensitive region.

\subsection{The effect of population agglomeration}

We assume in this section that population is normally distributed over the interval $[0,5]$, that is, population agglomerates around $x=2.5$. In order to underline the effect of population agglomeration, we increase total population to 10,500. Population in $x=2.5$ is almost 130 . Notice that although locations' land endowment is still equal to 300 , the part of $L$ devoted to housing in the central area is much larger than in the previous scenarios due to accrued population. ${ }^{6}$ In the areas neighbouring the center,

\footnotetext{
${ }^{6}$ Although the increase in total population is sizeable, a homogenous distribution of 10,500 people over 500 locations would imply 21 individuals per location. 21 individuals would need 21 units of land for housing, which is still a small figure with respect to the location's land endowment.
} 
the weight of population is similar to that in the benchmark scenario.
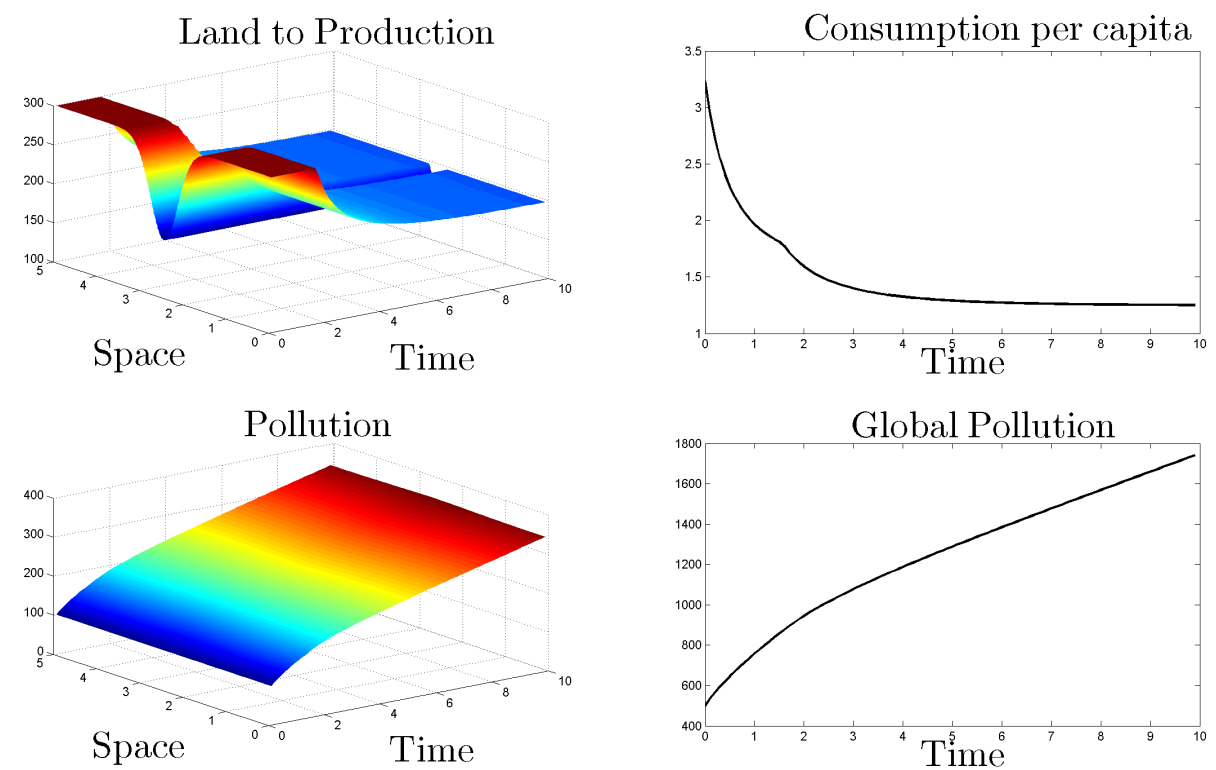

Figure 5: The role of population agglomeration (normal distribution).

We present two exercises. In the first one we compare the optimal trajectories under this population agglomeration with the benchmark scenario. Figure 5 shows that, due to concentrated population, locations in the central area cannot devote as much land to production as locations at the far ends. This means that agglomerations optimally "import" most of their consumption from the neighbouring areas, which are more specialised in production.

One could think then that agglomerations would be less polluted locally since most of their consumption comes from the periphery and housing does not pollute in this model. However, by the same token, agglomerations devote less land to abatement than the rest of locations. As a result, we observe an heterogeneous distribution not only of land, but also of local pollution. Even if local pollution tends to be homogeneous in space with time, slight spatial disparities persist since agglomerations cannot abate pollution coming from neighbouring regions. ${ }^{7}$

\footnotetext{
${ }^{7}$ Considering pollution due to housing and/or transportation would amplify this effect. Besides, these additional sources of pollution may have interesting implications, in particular if labour is a spatially mobile production factor. However, this is beyond the scope of this paper and we leave it for future research.
} 


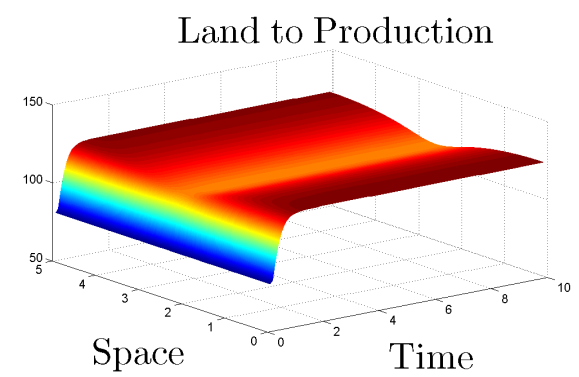

Pollution

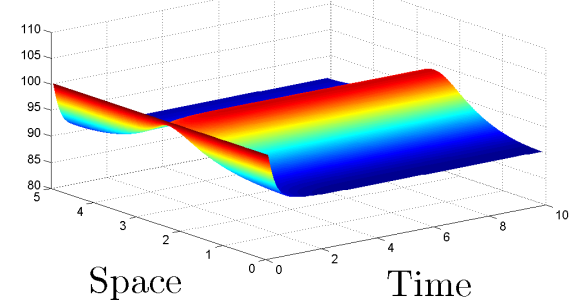

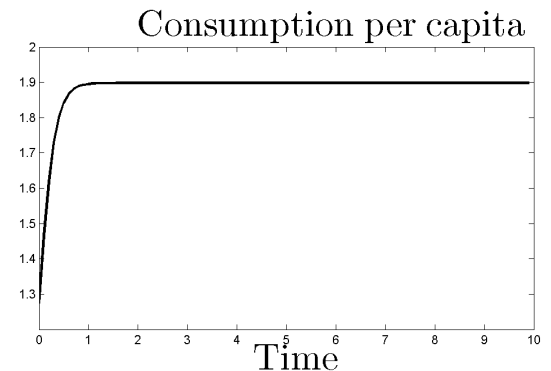

Global Pollution

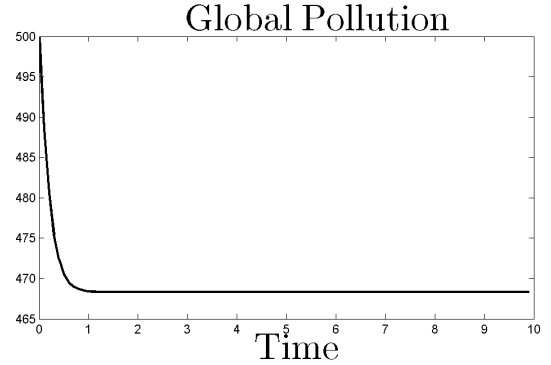

Figure 6: Normally distributed population with abatement productivity doubling.

Our last point above is reinforced in figure 6 , where we increase abatement productivity $(D)$ from 0.1 to 0.2 in all locations. In effect, both local and global pollution decrease in levels, but the spatial disparities are amplified. Moreover, due to the lower level of pollution, consumption per capita rises in the long-term. Finally, in contrast to the previous case, one should observe that all variables reach a steady state, which is characterized by lasting heterogeneity in land allocation and local pollution. As in section 5.2, this result points out the role of abatement as pollution stabilizer, which enhances consumption and enables the economy to reach a stable steady state.

\section{Concluding remarks}

Building on the Spatial Ramsey model introduced by Brito (2004) and Boucekkine et al. (2009), we propose in this paper a model to study optimal land use, encompassing land use activities, pollution and climate change. This benchmark set-up allows us to identify the spatial drivers behind the interaction between land use and the environment. Although land is spatially immobile by nature, location's actions affect the whole space through pollution and climate change. Indeed, we assume that pollution flows across locations resulting in both local and global damage. In particular, we 
illustrate this diffusion mechanism by means of considering the well-known Gaussian Plume equation.

In contrast to Boucekkine et al. (2009), Brock and Xepapadeas (2008a,b and 2010), and Xepapadeas (2010), we prove that the social optimum problem is wellposed. Therefore, the corresponding Pontryagin conditions are necessary are sufficient. Additionally, we illustrate the richness of our model adding a numerical analysis. In this regard, we adapt the algorithm developed in Camacho et al. (2008). This is an alternative method to the linear quadratic approximation of Brock and Xepapadeas (2008a,b and 2010), and Xepapadeas (2010), which allows us to provide global dynamics results.

In a near future, we would like to extend our benchmark set-up in several directions. From an empirical perspective, we will study the pertinence of our damage function, the role of local and global pollution and spatial sensitiveness. There are two theoretical extensions that seem extremely interesting. First, as stressed in footnote 2, we would add to our Gaussian plume the effect of advection due to, for instance, wind or water stream. Second, the introduction of human capital would allow us to study migration flows induced by climate change (see, for instance, Marchiori and Schumacher, 2011).

\section{References}

Adams R. (1989), "Global Climate Change and Agriculture: An Economic Perspective", American Journal of Agricultural Economics, 71(5), 1272-1279.

Adams R., S. Hamilton and B. McCarl (1986), "The Benefits of Pollution control: The Case of Ozone and U.S. Agriculture", American Journal of Agricultural Economics, 68(4), 886-893.

Akimoto H. (2003), "Global Air Quality and Pollution", Science, 302, 1716-1719.

Arya S. (1999), Air Pollution Meteorology and Dispersion, Oxford University Press, New York.

Boucekkine R., Camacho C. and Zou B. (2009), "Bridging the gap between growth theory and the new economic geography: The spatial Ramsey model", Macroeconomic Dynamics, 13, 20-45. 
Brock W. and Xepapadeas A. (2008a), "Diffusion-induced instability and pattern formation in infinite horizon recursive optimal control", Journal of Economic Dynamics \& Control, 32, 27452787.

Brock W. and Xepapadeas A. (2008b), "General Pattern Formation in Recursive Dynamical System Models in Economics", MPRA Paper 12305, University of Munich.

Brock W. and Xepapadeas A. (2010), "Pattern formation, spatial externalities and regulation in coupled economicecological systems", Journal of Environmental Economics and Management, 59, 149-164.

Brito P. (2004), "The dynamics of growth and distribution in a spatially heterogenous world", WP 13/2004, ISEG Working Papers.

Camacho C., Zou B. and Briani M. (2008), "On the dynamics of capital accumulation across space", European Journal of Operational Research, 186(2), 451-465.

Caputo M., M. Giménez, and M. Schlamp (2003), "Intercomparison of atmospheric dispersion models", Atmospheric Environment, 37, 2435-2449.

Chakir R. and A. Madignier (2006), "Analyse des changements dÕoccupation des sols en France entre 1992 et 2003", Economie Rurale, 296.

De Cara, S. and Rozakis, S. (2004), "Carbon sequestration through the planting of multi-annual energy crops: A spatial and dynamic assessment", Agricultural Economics Review, 5(1), 56-72.

De Cara, S., Houzé, M. and P. Jayet (2005), "Methane and nitrous oxide emissions from agriculture in the EU: A spatial assessment of sources and abatement costs", Environmental and Resource Economics, Vol. 32(4), 551-583.

Deschênes O. and M. Greenstone (2007), "The Economic Impacts of Climate Change: Evidence from Agricultural Output and Random Fluctuations in Weather ", The American Economic Review, 97, no 1, 354-385.

Desmet K. and E. Rossi-Hansberg (2009), "Spatial Growth and Industry Age", Journal of Economic Theory, 144(6), 2477-2502.

Desmet K. and E. Rossi-Hansberg (2010), "On spatial dynamics", The Journal of Regional Science, 50, 43-63. 
Duranton G. (2007), "Urban evolutions: The fast, the slow, and the still", American Economic Review, 97(1), 197-221.

Foley J., R. DeFries, G. Asner, C. Barford, G. Bonan, S. Carpenter, F. Chapin, M. Coe, G. Daily, H. Gibbs, J. Helkowski, T. Holloway, E. Howard, C. Kucharik, C. Monfreda, J. Patz, I. Prentice, N. Ramankutty and P. Snyder, (2005), "Global Consequences of Land Use", Science, 309, 570-572.

Freeze R., and J. Cherry (1979), Groundwater, Prentice-Hall, Englewood Cliffs, New Jersey.

French H., van der Zee, and A. Leijnse (2000), "Prediction uncertainty of plume characteristics derived from a small number of measuring points", Hydrogeology Journal, 8, 188-199.

Hadamard J., (1923), Lectureson the Cauchy Problem in Linear Partial Differential Equations. Yale University Press.

Haim D., R. Alig, A. Plantinga and B. Sohngen (2011), "Climate Change and Future Land Use in the United States: an Economic Approach", Climate Change Economics, $2(1), 27-51$.

Havlik P., U. Schneider, E. Schmid, H. Bottcher, S. Fritz, R. Skalsk, K. Aoki, S. De Cara, G. Kindermann, F. Kraxner, S. Leduc, I. McCallum, A. Mosnier, T. Sauer and M. Obersteiner (2011), "Global land-use implications of first and second generation biofuel targets", Energy Policy, Vol. 39(10), 5690-5702.

Heck W., W. Cure, J. Rawlings, L. Zaragoza, A. Heagle, H. Heggestad, R. Kohut, L. Kress and P. Temple, (1984), "Assessing Impacts of Ozone on Agricultural Crops: Crop Yield Functions and Alternative Exposure Statistics", Air Pollution Control Association, 34, 810-817.

Hotelling H. (1929), "Stability in competition", Economic Journal, 39, 41-57.

Houghton R., J. Hackler and K. Lawrence (1999), "The U.S. Carbon Budget: Contributions from Land-Use Change", Science, 285, 574-579.

Houghton R. and J. Hackler (2001), "Carbon Flux to the Atmosphere from Land-Use Changes: 1850 to 1990", ORNL/CDIAC-131, NDP-050/R1 (Oak Ridge National Laboratory, Oak D Ridge). 
Jeong H., E. Kim, K. Suh, W. Hwang, M. Han, and H. Lee (2005), "Determination of the source rate released into the environment from a nuclear power plant", Radiation Protection Dosimetry, 113, 308-313.

Kalnay E. and M. Cai (2003), "Impact of Urbanization and land-use change on climate", Nature, 423, 528-531.

Marchiori L. and I. Schumacher (2011), "When Nature Rebels: International Migration, Climate Change and Inequality", Journal of Population Economics, 24(2), 569600 .

Matson P., W. Parton, A. Power and M. Swift (1997), "Agricultural intensification and Ecosystem Properties", Science, 277, 504-509.

Nicholls R. and A. Cazenave (2010), "Sea-Level Rise and Its Impact on Coastal Zones", Science, 328, 1517-1520.

Nicholls R., N. Marinova, J. Lowe, S. Brown, P. Vellinga, D. de Gusmao, J. Hinkel and R. Tol, (2011), "Sea-level rise and its possible impacts given a 'beyond $4^{\circ} \mathrm{C}$ world' in the twenty-first century", Philosophical Transactions of the Royal Society A, 369, 161-181.

Nowak D., D. Crane and J. Stevens (2006), "Air pollution removal by urban trees and shrubs in the United States", Urban Forestry \& Urban Greening, 4, 115-123.

Olesen J. and M. Bindi (2002), "Consequences of climate change for European agricultural productivity, land use and policy", European Journal of Agronomy, 16, 239-262.

Pao C. (1992), Nonlinear Parabolic and Elliptic Equations, Plenum Press, New York.

Plantinga A. (1996), "The Effect of Agricultural Policies on Land Use and Environmental Quality", American Journal of Agricultural Economics, 78(4), 1082-1091.

Ragot L. and K. Schubert (2008), "The optimal carbon sequestration in agricultural soils: do the dynamics of the physical process matter?", Journal of Economic Dynamics \& Control, 32(12), 3847-3865.

Raymond J. and Zidani H. (1998), "Pontryagin's principle for state-constrained control prob- lems governed by parabolic equations with unbounded controls", SIAM Journal on Control and Optimization, 36(6), 1853-1879. 
Raymond J. and Zidani H. (2000), "Time optimal problems with Boundary controls", Differential and Integral Equations, Vol 13, 1039-1072.

Roberts O. (1924), "The theoretical scattering of smoke in a turbulent atmosphere", Philosophical Transactions of the Royal Society, A, 104, 640-654.

Salop S. (1979), "Monopolistic competition with outside goods", Bell Journal of Economics, 10, 141-156.

Settles G. (2006), "Fluid mechanics and homeland security", Annual Review of Fluid Mechanics, 38, 87-110.

Stockie J. (2011), "The Mathematics of Atmospheric Dispersion Modeling", Siam Review, 53(2), 349-372.

Sutton O. (1932), "A theory of eddy diffusion in the atmosphere", Proceeding of the Royal Society, A, 135, 143-165.

Sutton, O. (1947a), "The problem of diffusion in the lower atmosphere", Quarterly Journal of the Royal Meteorological Society, 73, 257-281.

Sutton, O. (1947b), "The theoretical distribution of airborne pollution from factory chimneys", Quarterly Journal of the Royal Meteorological Society, 73, 426-436.

Tilman D., P. Reich, J. Knops, D. Wedin, T. Milke and C. Lehman (2001), "Diversity and Productivity in a Long-Term Grassland Experiment", Science, 294, 843-845.

U.S. Environmental Protection Agency (1984), Air Quality Criteria for Ozone and Other Photochemical Oxidants, vol. 3. EPA-600/8-84-020A, Washington DC.

Weitzman M. (2009), "On modeling and interpreting the economics of catastrophic climate change", The Review of Economics and Statistics, 91(1), 1-19.

Xepapadeas A. (2010), 'The spatial dimension in environmental and resource economics", Environmental and Development Economics, 15, 747-754. 


\section{Appendices}

\section{A Proposition 1 proof}

We shall proof that the system of partial differential equations constraining the policy maker's objective function has a unique solution for every choice of feasible functions $(c, l)$. This proves the existence of at least a solution to the policy maker's problem. In this regard, we shall begin with converting the set of constraints into a system of parabolic differential equations.

First, notice that we can take the derivative of $P$ with respect to $t$ and we use the law of motion for $p$ in $\mathcal{P}$ to obtain:

$$
P_{t}(t)=\int_{\mathbb{R}} p_{t}(x, t) d x=\int_{\mathbb{R}}\left(p_{x x}(x, t)+\Omega(p, P, x) A(x, t) F(l(x, t))-G(1-l-f(x))\right) d x,
$$

which implies that

$P_{t}(t)=\left.p_{x}(x, t)\right|_{x \rightarrow \infty}-\left.p_{x}(x, t)\right|_{x \rightarrow-\infty}+\int_{\mathbb{R}}[\Omega(p, P, x) A(x, t) F(l(x, t))-G(1-l-f(x))] d x$.

Since $\lim _{x \rightarrow \pm \infty} p_{x}(x, t)=0$, we have that

$$
P_{t}(t)=\int_{\mathbb{R}}[\Omega(p, P, x) A(x, t) F(l(x, t))-G(1-l-f(x))] d x .
$$

Our initial set of constraints can be written as a system of parabolic equations. Indeed, we can interpret (A.1) as a partial differential equation, with the second order operator equal to zero. We would need to artifitially transform $P$ into a two dimensional function, $P(x, t) \equiv P(t), \forall x \in \mathbb{R}$. Then:

$$
\left(P^{\prime}\right)\left\{\begin{array}{l}
p_{t}(x, t)-p_{x x}(x, t)=\Omega(p, P, x) A(x, t) F(l(x, t))-G(1-l-f(x)), \\
P_{t}(x, t)=\int_{\mathbb{R}^{+}}[\Omega(p, P, x) A(x, t) F(l(x, t))-G(1-l-f(x))] d x \\
p(x, 0)=p_{0}(x) \geq 0 \\
\lim _{x \rightarrow \pm \infty} p_{x}(x, t)=0 \\
P(x, 0)=\int_{\mathbb{R}} p_{0}(x) d x \\
\lim _{x \rightarrow \pm \infty} P_{x}(x, t)=0,
\end{array}\right.
$$

for all $(x, t) \in \mathbb{R} \times \mathbb{R}^{+}$. As in Camacho et al. (2008) and Boucekkine et al. (2009), for any given finite $T$, if $(x, t) \in \mathbb{R} \times(0, T]$, Pao (1992) proves the existence of a solution to 
this kind of equations after transforming the integral term in each dynamic equation. We proceed to the following change of variable $\Pi(x, t)=e^{-\gamma t} P(x, t)$ and we obtain:

$$
\Pi(x, t)_{t}+\gamma \Pi(x, t)=e^{-\gamma t} \int_{\mathbb{R}}\left[\Omega\left(p, e^{\gamma t} \Pi, x\right) A(x, t) F(l(x, t))-G(1-l-f(x))\right] d x .
$$

Then, we define function $\pi(t)$ as

$$
\pi(t)=e^{-\gamma t} \int_{\mathbb{R}}\left[\Omega\left(p, e^{\gamma t} \Pi, x\right) A(x, t) F(l(x, t))-G(1-l-f(x))\right] d x .
$$

Notice that since the integrand is globally Lipschitz continuous, so it is function $\pi$. We have to study now the existence of solution of the following system of equations:

$$
\left\{\begin{array}{l}
p_{t}(x, t)-p_{x x}(x, t)=\Omega(p, P, x) A(x, t) F(l(x, t))-G(1-l-f(x)), \\
\Pi_{t}(x, t)+\gamma \Pi(x, t)=\pi(t), \\
p(x, 0)=p_{0}(x) \geq 0, \quad \lim _{x \rightarrow \pm \infty} \frac{\partial p(x, t)}{\partial x}=0, \\
\Pi(x, 0)=\int_{\mathbb{R}} p_{0}(x) d x \\
\lim _{x \rightarrow \pm \infty} \Pi_{x}(x, t)=0 .
\end{array}\right.
$$

We can then apply theorem 12.1 in chapter 8 in Pao (1992) to ensure the existence of a unique solution to the system of parabolic equations for every choice of the couple $(l, c)$.

\section{B Proposition 2 proof}

We can take the first order derivative of the value function $V$ with respect to $\epsilon$, the size of the deviation. There is a main difference with the literature in spatial growth in continuous space which emanates from the diffusion factor. Indeed, in the present model we have that:

$$
\begin{aligned}
\int_{0}^{T} \int_{\mathbb{R}} q(x, t) p_{x x}(x, t) d x d t & =\left.\int_{\mathbb{R}^{+}} q(x, t) p_{x}(x, t)\right|_{0} ^{R} d t-\left.\int_{\mathbb{R}^{+}} q_{x}(x, t) p(x, t)\right|_{-\infty} ^{\infty} d t+ \\
& +\int_{\mathbb{R}^{+}} \int_{\mathbb{R}} q_{x x}(x, t) p(x, t) d x d t
\end{aligned}
$$

and as usual: 


$$
\int_{\mathbb{R}^{+}} \int_{\mathbb{R}} q(x, t) p_{t}(x, t) d x d t=\left.\int_{\mathbb{R}} p(x, t) q(x, t)\right|_{0} ^{\infty}-\int_{\mathbb{R}} \int_{\mathbb{R}} p(x, t) q_{t}(x, t) d x d t .
$$

We then obtain:

$$
\begin{aligned}
& \frac{\partial V(c, l, p, P)}{\partial \epsilon}= \\
& =\int_{\mathbb{R}^{+}} \int_{\mathbb{R}} u^{\prime}(c(x, t)) f(x) g(t) \kappa(x, t) d x d t-\int_{\mathbb{R}^{+}} \int_{\mathbb{R}} g(t) \pi(x, t)\left[q_{t}(x, t)+q_{x x}(x, t)\right]+ \\
& +\int_{\mathbb{R}^{+}} \int_{\mathbb{R}} g(t) q(x, t) \Omega_{1}(p, P, x) A(x, t) F(l(x, t)) \pi(x, t) d x d t+ \\
& +\int_{\mathbb{R}^{+}} \int_{\mathbb{R}} g(t) q(x, t)\left[\Omega_{2}(p, P, x) A(x, t) F(l(x, t)) \Pi(t)+\Omega(p, P, x) A(x, t) F^{\prime}(l(x, t)) L(x, t)\right] d x d t+ \\
& +\int_{\mathbb{R}^{+}} \int_{\mathbb{R}} g(t) q(x, t) G^{\prime}(1-l-f(x)) L(x, t) d x d t- \\
& -\int_{\mathbb{R}^{+}} m(t) g(t)\left(\Pi(t)-\int_{\mathbb{R}} \pi(x, t) d x\right) d t- \\
& -\int_{\mathbb{R}^{+}} n(t) g(t)\left(\int_{\mathbb{R}} \kappa(t) f(x) d x\right) d t+ \\
& +\int_{\mathbb{R}^{+}} n(t) g(t)\left(\int_{\mathbb{R}}\left[\Omega_{1}(p, P, x) A F(l) \pi(x, t)+\Omega_{2}(p, P, x) A F(l) \Pi(t)+\Omega(p, P, x) A F^{\prime}(l) L(x, t)\right] d x\right) d t .
\end{aligned}
$$

To obtain the necessary conditions, we can group the elements multiplying $\kappa, \pi$, $L$ and $P$, and equate them to zero. If all factors multiplying deviations from optimal values for $c, p, P$ and $l$ are equal to zero, we obtain that the deviation $\epsilon$ is optimal, i.e., $\frac{\partial V}{\partial \epsilon}=0$. We would need then:

$$
\begin{cases}\kappa: & u^{\prime}(c)=n(t), \\ \pi: & q_{t}+q_{x, x}=(q+n) \Omega_{1} A F(l)+m, \\ \Pi: & m(t)=R \Omega_{2} A F(l)(q+n), \\ L: & q\left(\Omega A F^{\prime}+G^{\prime}\right)+n(t)\left(\Omega A F^{\prime}\right)=0 .\end{cases}
$$

To these conditions, we need to add the following transversality conditions:

$$
\left\{\begin{array}{l}
\lim _{x \rightarrow \pm \infty} q_{x}=0 \\
\lim _{t \rightarrow \infty} p q=0
\end{array}\right.
$$

We obtain the final version of the first order conditions substituting $m(t)$ by $R \Omega_{2} A F(l)(q+n)$ into the dynamic equation for $q$. 


\section{Corollary 1 proof}

We can read in the first equation of the system (A.5) in the previous proof that $u^{\prime}(c(x, t))=n(t), \forall(x, t)$. Hence, neither $u^{\prime}(c(x, t))$ nor $c(x, t)$ depend on space.

\section{Computational setting}

Since the time horizon is finite, we can reverse time in the equation describing the dynamic behaviour of $q$ in time and space in (A.3). Calling $h(x, t):=q(x, T-t)$, we obtain the following system of parabolic differential equations where we have removed the independent variables $(x, t)$ for simplicity reasons, writing $(x, T-t)$ when necessary:

$$
\left\{\begin{array}{l}
p_{t}-p_{x x}=\Omega(p, P, x) A F(l)-G(1-l-f), \\
h_{t}-h_{x x}= \\
=-\left[\Omega_{1}(p(x, T-t), P(x, T-t), x)+R \Omega_{2}(p(x, T-t), P(x, T-t), x)\right] \times \\
\times A F(l)\left[u^{\prime}(c(T-t))+h\right], \\
{\left[u^{\prime}(c)+h(x, T-t)\right] \Omega(p, P, x) A F^{\prime}(l)+h(x, T-t) G^{\prime}(1-l-f)=0,} \\
c(t)=\frac{\int_{0}^{T} \int_{R} \Omega(p, P, x) A F(l) d s d t}{\int_{R} f(s) d s}, \\
P(t)=\int_{R} p d x \\
p(x, 0)=p_{0}(x) \geq 0, \\
\lim _{x \rightarrow\{0, R\}} p_{x}(x, t)=0, \\
\lim _{x \rightarrow\{0, R\}} h_{x}(x, t)=0, \\
\lim _{t \rightarrow T} p(x, t) h(x, T-t)=0,
\end{array}\right.
$$

for $(x, t) \in[0, S] \times[0, T]$. We simulate the system above using a finite difference approximation. The idea of this method is to replace the second derivative with respect to space with a central difference quotient in $x$, and replace the derivative with respect to time with a forward difference in time. In order to implement this approximation we need to set up a grid in our space $[0, R] \times[0, T]$. The points in this grid are couples $(j \Delta x, n \Delta t)$ for $j=0,1, \ldots, J$ and $n=1,2, \ldots, N$, where $J \Delta x=R$ and $N \Delta t=T$. Then, if $v$ is a function defined on the grid, we write $v(j \Delta x, n \Delta t)=v_{j}^{n}$. 
Let us provide an example. If we want to use a finite difference approximation for the parabolic differential equation $\frac{\partial v}{\partial t}=\frac{\partial^{2} v}{\partial x^{2}}$, we write: ${ }^{8}$

$$
\frac{v_{j}^{n+1}-v_{j}^{n}}{\Delta t}=\frac{1}{\Delta x^{2}}\left(v_{j+1}^{n+1}-2 v_{j}^{n+1}+v_{j-1}^{n+1}\right) .
$$

We can write (A.6) as

$$
\begin{gathered}
\frac{p_{j}^{n+1}-p_{j}^{n}}{\Delta t}-\frac{1}{\Delta x^{2}}\left(p_{j+1}^{n+1}-2 p_{j}^{n+1}+p_{j-1}^{n+1}\right)=\Omega\left(p_{j}^{n}, P_{j}^{n}, j\right) A F\left(l_{j}^{n}\right)-G\left(1-l_{j}^{n}-f_{j}^{n}\right), \quad(A \\
\frac{h_{j}^{n+1}-h_{j}^{n}}{\Delta t}-\frac{1}{\Delta x^{2}}\left(h_{j+1}^{n+1}-2 h_{j}^{n+1}+h_{j-1}^{n+1}\right)= \\
=-\left(\Omega_{1}\left(p_{j}^{T-n}, P_{j}^{T-n}, j\right)+R \Omega_{2}\left(p_{j}^{T-n}, P_{j}^{T-n}, j\right)\right) A F\left(l_{j}^{T-n}\right)\left[u^{\prime}\left(c^{T-n}\right)+h(x, t)\right]
\end{gathered}
$$

$$
\left[u^{\prime}\left(c^{n}\right)+h_{j}^{T-n}\right] \Omega\left(p_{j}^{n}, P_{j}^{n}, j\right) A F^{\prime}\left(l_{j}^{n}\right)+h_{j}^{T-n} G^{\prime}\left(1-l-f_{j}^{n}\right)=0
$$

with $P^{n}=\sum_{j=0}^{J} p_{j}^{n}$ and $c^{n}=\frac{\sum_{j=0}^{J}\left(\Omega\left(p_{j}^{n}, P_{j}^{n}, j\right) A F\left(l_{j}^{n}\right)\right)}{\sum_{j=0}^{J} f(j)}$.

To these equations, we add the border conditions $p_{J-1}^{n}=p_{J}^{n}$ and $h_{J-1}^{n}=h_{J}^{n}, \forall n=$ $1,2, \ldots, N$ and the definition of $P$.

\section{D.1 The algorithm}

We adapt the algorithm developed in Camacho et al. (2008) to problem (A.6). There are still some differences: we need an initial guess for matrix $\left\{h_{j}^{n}\right\}_{j=1 \ldots J}^{n=1 \ldots N}$. Depending on this guess, we obtain a land distribution $\left\{l_{j}^{n}\right\}_{j=1 \ldots J}^{n=1 \ldots N}$ and then a first approximation to consumption. To improve the convergence speed we run an intermediate loop to improve the initial guess for $c$ and $l$.

\footnotetext{
${ }^{8}$ This method is called the implicit finite difference approximation. Other approximation schemes exist but the implicit one is unconditionally stable, meaning that it is stable without restrictions on the relative size of $\Delta t$ and $\Delta x$. It also allows us to use a larger time step and to save this way computational time.
} 
In order to reduce the computational load, we compute $P^{n}=\sum_{j=0}^{J} p_{j}^{n-1}$. Although this is just an approximation, we underline that the distance between $P(t)$ and $P(t-\Delta t)$ is infinitesimal since $P$ is a continuous function. In the same manner, we compute $c^{n}=\frac{\sum_{j=0}^{J}\left(\Omega\left(p_{j}^{n-1}, P_{j}^{n}, j\right) A F\left(l_{j}^{n}\right)\right)}{\sum_{j=0}^{J} f(j)}$.

\section{Step 1: Initialization}

We choose an initial distribution for air pollution $p_{0}=\left\{p_{0, j}\right\}$, land allocation $l_{0}=\left\{l_{0, j}\right\}$ and three stopping parameters $\epsilon_{i}$ for $i=1,2,3$. We compute $P^{0}=$ $\sum_{j=0}^{J} p_{j}^{0}$. We assume an initial guess for $\left\{h_{j}^{\prime n}\right\}_{j=1 \ldots J}^{n=1 \ldots N}$.

\section{Step 2: Iteration}

We repeat the following scheme until the euclidean distance between two consecutive matrices $q$ is smaller than $\epsilon_{1}$ or until the number of iterations equals a fixed number $K$.

For every $n=1, \ldots, N$ and given $p_{n-1}, l_{n-1}, P_{n-1}$, we compute

$$
c_{n}=\frac{\sum_{j=0}^{J}\left(\Omega\left(p_{j}^{n-1}, P_{j}^{n}, j\right) A F\left(l_{j}^{n-1}\right)\right)}{\sum_{j=0}^{J} f(j)} .
$$

Step 2.1: Improvement of the first guess

With $c_{n}$ and the guess $\left\{h_{j}^{\prime n}\right\}_{\{j=1, \ldots, J\}}$, using (A.11), we obtain a guess for $\left\{l_{j}^{n}\right\}$. We recompute $c_{n}$ with $\left\{l_{j}^{n}\right\}$ instead of $\left\{l_{j}^{n-1}\right\}$. We iterate the process until the euclidean distance between two consecutive outcomes for $c_{n}$ is smaller than $\epsilon_{2}$.

Step 2.2: Upwind

At every $n$ we compute $p_{n}^{j}$ for $j=1, \ldots, J$ with the resulting $c_{n}$ and $\left\{l_{j}^{n}\right\}$, using the upwind algorithm applied to equation (A.10). Then, using (A.10) we compute a new guess for $\left\{h_{j}^{n}\right\}_{j=1 \ldots J}^{n=1 \ldots N}$ and compute its distance to $\left\{h_{j}^{\prime n}\right\}_{j=1 \ldots J}^{n=1 \ldots N}$. If the distance is smaller than $\epsilon_{3}$, then STOP. If not, we repeat Step 2. 